\title{
Analysis of Mechanical Properties and Micro Structure of Body Valve Bolts, Alloy Steel Grade B7 Material as a Result of Offshore Application
}

\author{
Qamaruddin ${ }^{1}$, Mochamad Iwan Nur Irawan ${ }^{2}$, Dwi Wahyuni Wulandari ${ }^{3}$, Iskandar Adji \\ Purnomo ${ }^{4}$ \\ \{qamaruddin@stimar.ac.id\} \\ Sekolah Tinggi Ilmu Maritim (STIMar) “AMI” Jakarta ${ }^{1,3,4}$, Universitas Islam “45” (UNISMA) Bekasi ${ }^{2}$

\begin{abstract}
The objective of this research is to examine the mechanical properties and micro structure of body valve bolts using the alloy steel grade B7 material after being applied for more than 12 months on offshore location. The experimental steps conducted in the research were specimens check based on maker specification, preparation of specimens, tensile and hardness tests for mechanical properties and metallography for micro structure, analysis and conclusion. The total specimens were 18 bolts. Based on the research, it was found that the tensile strength $94.9 \mathrm{kgf} / \mathrm{mm} 2$ and hardness $30.0 \mathrm{HRC}$, the micro structure was consisting of ferit and pearlit. Comparing the result of testing of the used bolts to the new ones and the standard ones by ASTM A193, it can be concluded the used bolts remained applicable on condition that there is no defect and corrosion existing.
\end{abstract}

Keywords: Mechanical Properties, Micro Structure, Body Valve Bolts, Alloy Steel Grade B7.

\section{Introduction}

One of the most important parts of a valve is the body bolt, because it holds the load as long as the valve unit is used. In addition to the size and type of material, it must be in accordance with the conditions of use, this bolt also needs to be ensured of its reliability after long-term use (over 1 year), especially if the valve is installed in an area that is exposed to a corrosive outside environment.

For each valve bolt check, PT. OSA Industries Indonesia conduct non-destructive or NDT (Non Destructive Test) and the body valve bolt can be reused if the NDT results are good.

Based on the incident experienced by one of the clients of PT. OSA Industries Indonesia, there were 3 (three) cases of the body valve bolt being broken during operation and the valve was split causing a leak of gas and oil spoiled out and the drilling division had to be stopped. The customer requested that each valve repair be replaced by a new bolt body.

From the experience above, it seemed necessary to conduct research and analysis in the form of property mechanical testing (tensile test, hardness test) and microstructure of the body valve bolts. This is to ensure the reliability of the bolt after being used (over 1 year) in the offshore field. 


\section{Methodology}

The flow of research is roughly depicted as shown in Figure 1.

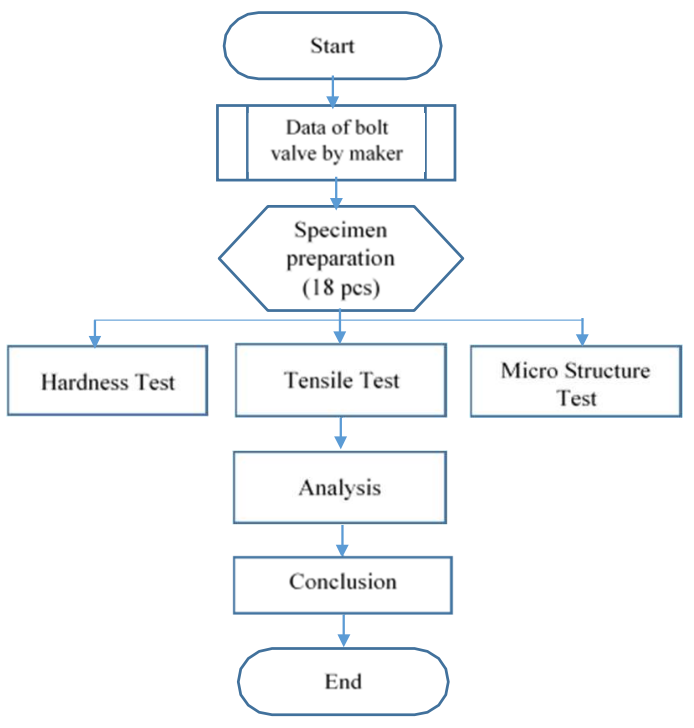

Figure 1: The flow of research

The research was starting from examining data of the bolt specified by maker, specimen preparation, then conducting hardness test by using Rockweel, Tensile test using ASTM F-606 and microstructure test by 500x magnification. After the respective tests, conducting analysis and finally drawing conclusion.

\section{a. Material preparation}

Specimen/Material used for testing with total 18 pcs consisting of:

a. Tensile Test: New Bolts (3 pcs) and Used Bolts (3pcs)

b. Hardness Test: New Bolts ( 3 pcs) and Used Bolts (3 pcs)

c. Micro Structure: New Bolts (3 pcs) and Used Bolts (3 pcs)

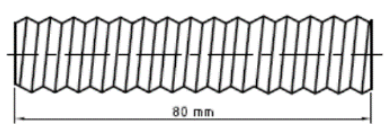

(a)
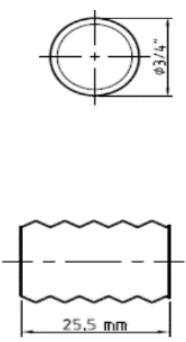

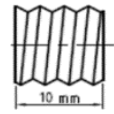

(b)

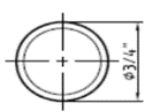

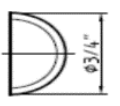

(c)

Fig.2. Specimen dimension for testing (a) Tensile test, (b) hardness test, (c) micro structure 


\section{b. Equipments}

- Cutting machine

- Grinding machine

- Lapping machine

- Polishing machine

- Lathe

- Tensile test machine

- Hardness test (Rockwell C)

- Vernier Caliper

- Optical microscope

\section{c. Experimental process}

The bolt was processed as shown in Figure 2 by using the respective machine. For micro structure purpose, the specimen was being polished, etched by nital and picture taken by optical microscope 500x magnification.

\section{Result and Discussion}

The chemical composition of new bolts and used ones is shown in Table 1 and 2. In figure 3 , it can be seen the sample of certificate released by maker shown in Table 3 . Table 3 represents the result of hardness test and table 4 shows the result of tensile test. Figure 4 shows the representation of the microstructure of new bolts and used ones.

Fig.3. Sample of certificate by maker

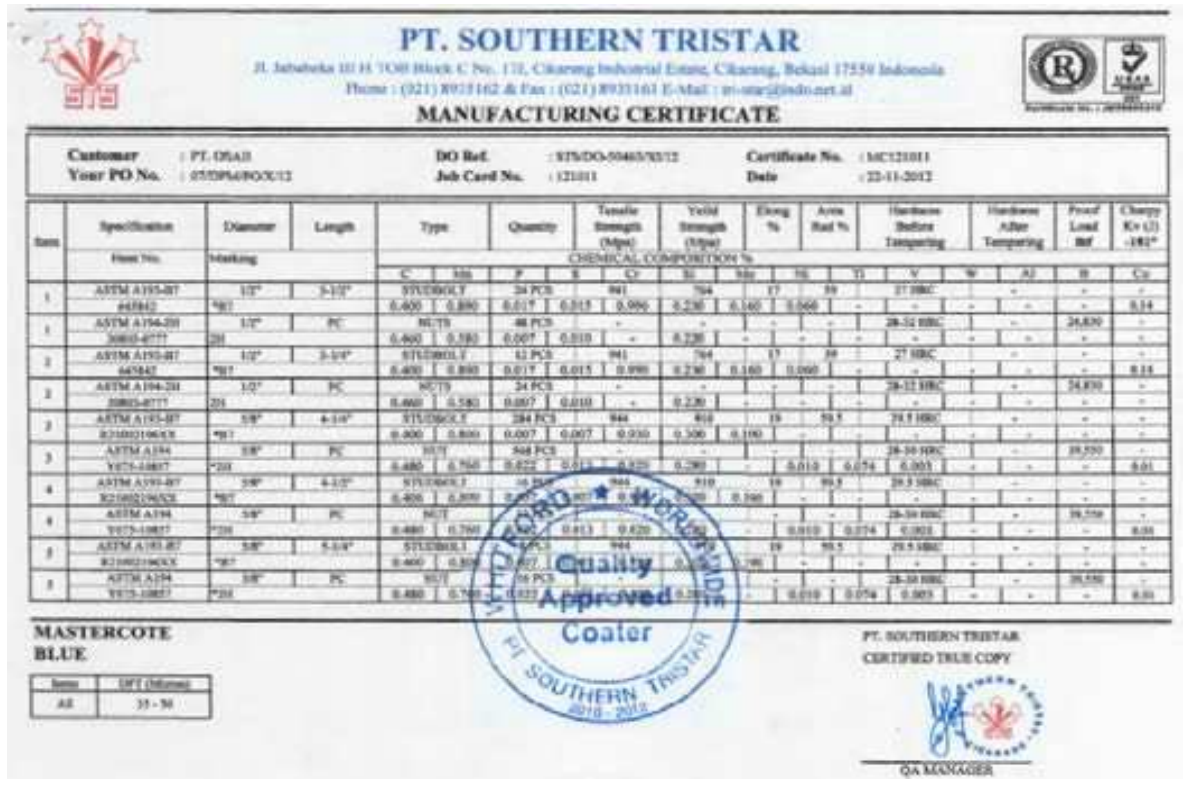


Table 1. The chemical composition of New bolt ASTM 193

\begin{tabular}{cccccccc}
\hline $\begin{array}{l}\text { Specimen/ } \\
\text { Element }\end{array}$ & $\mathrm{C}$ & $\mathrm{Mn}$ & $\mathrm{P}(\max )$ & $\mathrm{S}(\max )$ & $\mathrm{Cr}$ & $\mathrm{Si}$ & $\mathrm{Mo}$ \\
\hline standard & $0.37-0.49$ & $0.65-1.10$ & 0.035 & 0,04 & $0.75-1.20$ & $0.15-0.35$ & $0.15-0.25$ \\
PT.X & 0.384 & 0.715 & 0.018 & 0.011 & 1.010 & 0.307 & 0.20 \\
PT.Y & 0.370 & 0.780 & 0.011 & 0.007 & 0.970 & 0.210 & 0.15 \\
PT.Z & 0.383 & 0.860 & 0.016 & 0.035 & 1.078 & 0.150 & 0.18 \\
\hline
\end{tabular}

Table 2. The chemical composition of Used bolt ASTM 193

\begin{tabular}{cccccccc}
\hline scimen/El ement & $\mathrm{C}$ & $\mathrm{Mn}$ & $\mathrm{P}(\max )$ & $\mathrm{S}(\max )$ & $\mathrm{Cr}$ & $\mathrm{Si}$ & $\mathrm{Mo}$ \\
\hline standard & $0.37-0.49$ & $0.65-1.10$ & 0.035 & 0,04 & $0.75-1.20$ & $0.15-0.35$ & $0.15-0.25$ \\
BV-0676B & 0.374 & 0.920 & 0.027 & 0.009 & 0.967 & 0.234 & 0.21 \\
BV-0035B & 0.379 & 0.927 & 0.019 & 0.007 & 1.030 & 0.329 & 0.19 \\
CHV-0078B & 0.373 & 0.777 & 0.015 & 0.007 & 0.918 & 0.237 & 0.18 \\
\hline
\end{tabular}

Table 3. The Hardness Test of New and Used Bolts (Load 150 Kgf) Standar ASTM A193 Grade B7

\begin{tabular}{lccc}
\multicolumn{4}{c}{$(\max .35$ HRC) } \\
\hline Specimen & Average & ASTM A193 (max) & Note \\
& & & \\
\hline New Bolts & 33.2 & 35.0 & OK \\
Used Bolts & 30.0 & 35.0 & OK \\
\hline
\end{tabular}

Table 4. The Tensile Test of New and Used Bolts (Kgf/mm2)

\begin{tabular}{lccc}
\hline Specimen & Average & ASTM A193 (min) & Note \\
& & & \\
\hline New Bolts & 93.6 & 87.9 & OK \\
Used Bolts & 94.9 & 87.9 & OK \\
\hline
\end{tabular}

(a)

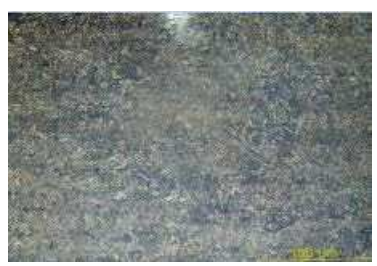

(b)

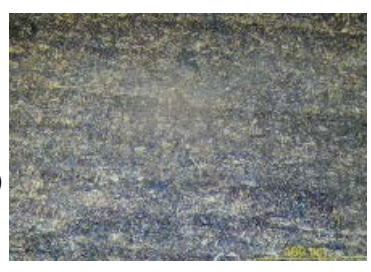

Fig. 4. Microstructure (a) New bolt, (b) Used bolt (500x)

Based on the result of the hardness test and tensile test as depicted in Table 3 and 4, the values of the used body valve bolt and the values of the new one have relatively the same, although the 
spread of the used body valve bolt occurs after use or the locking process in the field which caused the material structure to develop and this resulted in a reduction of the value of the hardness and strength.

In Figure 4, micro structure observations on the new bolt of this specimen show the pearlite (dark) region is relatively more dominant than the ferrite phase (light color). The parent metal contains $0.370 \%$ carbon so it is said that this carbon steel is hypoeutectoid.

\section{Conclusion}

Based on the result and discussion, the following conclusion can be drawn is comparing the result of the test both hardness and tensile test between the new bolts and the used ones, the used ones remain useable. The microstructure of the new bolts and used ones were consisting of ferit and pearlit phases which belong to carbon steel

\section{References}

[1] https://kupdf.net/download/astm-f-606-pdf_5b0a0929e2b6f5962fc5942c pdf (accessed 11-Nov2019

[2] https://www.a193bolts.com > grades (accessed 11-Nov-2019)

[3] ASME B16.34, Valve, Flange, Threaded and Welding End (2009)

[4] ASTM A350 Standard Specification for Carbon and Low-Alloy Steel Forgings, Requiring Notch Toughness Testing for Piping Components (2002) 